\title{
A scoping review of occupational therapy interventions in the treatment of people with substance use disorders
}

\author{
Deirdre Anne Ryan \\ Occupational Therapy Department, St Patrick's Mental Health Services, Dublin, Ireland, and \\ Pauline Boland \\ School of Allied Health, Ageing Research Centre, Health Research Institute, University of Limerick, Limerick, Ireland
}

\begin{abstract}
Purpose - Diagnosis of substance use disorders and addictive behaviours are growing worldwide. It is timely to examine and collate literature on the nature of occupational therapy intervention in this field, to increase understanding of current practice and inform future directions. The purpose of this paper is to source and synthesise literature on occupational therapy interventions used in the treatment of people experiencing addiction.

Design/methodology/approach - Four databases were searched in August 2019. A total of 597 titles were screened, and 18 studies with varying methods met inclusion criteria. A narrative synthesis of the included literature was arranged into themes to summarise key findings.

Findings - Findings were grouped into three themes about occupational therapy provision to people experiencing addiction: single occupation focused intervention; skills training (including sub-themes on daily living skills and vocational skills); and establishing a community-based sober routine.

Research limitations/implications - Further research on this topic should focus on efficacy of treatments and build on current findings to develop more rigorous research with appropriate sample sizes to support evidence-based practice.

Originality/value - This study presents a synthesis of how occupational therapy interventions have been used to treat people experiencing addiction issues. Findings indicate occupational therapy appears to fit well within addiction treatment and assert that occupational therapy is most supportive when interventions go beyond the teaching of skills alone to prioritise occupational engagement and client centred practice.
\end{abstract}

Keywords Occupational therapy, Recovery, Substance use, Addiction recovery, Addiction treatment

Paper type General review

\section{Introduction}

Addiction is a dependence syndrome consisting of behavioural, cognitive and physiological phenomena that develop after repeated substance use (WHO, 2013). These phenomena include a strong desire to engage with the substance or behaviour, difficulties controlling use, persisting with use despite harmful consequences and prioritising addictionrelated activities above all others (WHO, 2013). The World Drug Report (UNODC, 2017) estimates there are 255 million illicit drug users globally. WHO (2014) reports more than half of Irish adults could be classed as harmful drinkers, with the National Institute for Health and Care Excellence (NICE) (2010, p. 5) defining harmful drinking "as a pattern of alcohol consumption causing health problems directly related to alcohol." With substance use increasing, health and addiction services face a challenge requiring cross-sectoral innovative approaches.

The current issue and full text archive of this journal is available on Emerald Insight at: https://www.emerald.com/insight/2398-8819.htm

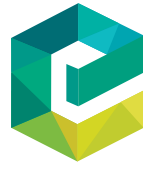

Irish Journal of Occupational Therapy

49/2 (2021) 104-114

Emerald Publishing Limited [ISSN 2398-8819]

[DOI 10.1108/IJOT-11-2020-0017]
Occupational therapists are well positioned to support people with substance use disorders, because of their holistic focus and skills in occupational enablement (Amorelli, 2016) and have been part of inpatient addiction treatment as far back as 1952 (Hossack, 1952). Although there are some guides for potential occupational therapy for people experiencing substance use and addictive behaviours (Lancaster and Chacksfield, 2014; Wasmuth et al., 2014), these can be limited

(C) Deirdre Anne Ryan and Pauline Boland. Published in Irish fournal of Occupational Therapy. Published by Emerald Publishing Limited. This article is published under the Creative Commons Attribution (CC BY 4.0) licence. Anyone may reproduce, distribute, translate and create derivative works of this article (for both commercial and non-commercial purposes), subject to full attribution to the original publication and authors. The full terms of this licence maybe seen at http://creativecommons.org/licences/ by $/ 4.0 /$ legalcode

Research ethics: No ethical approval was required for this study.

Conflict of interest: The authors confirm that there is no conflict of interest.

Funding: This research received no specific grant from any funding agency in the public, commercial or not-for-profit sectors.

Received 12 November 2020

Revised 12 March 2021

14 July 2021

7 October 2021

Accepted 12 October 2021 
by opinion or are descriptions of potential rather than actual clinical interventions.

Previous systematic reviews have not specifically identified the range of interventions carried out exclusively by occupational therapists working with people experiencing substance use or addictive behaviours (Wasmuth et al., 2014; Rojo-Mota et al., 2017). However, Rojo-Mota et al. (2017) noted an emerging trend that occupation-based interventionists are increasingly recognising the need for effectiveness studies. These studies could support the many occupational therapists who report reduced confidence addressing issues for people with substance use disorders with up-to-date evidence (Thompson, 2007).

The details of how and when occupational therapists work with people experiencing substance use disorders remains unclear, therefore collating and examining the existing evidence should clarify the design and delivery of existing interventions, likely outcomes for clients, their families and supportive services and the sustainability of change in sober occupations over time. A scoping review approach was chosen to guide data collection and analysis as this review design is suited to mapping the data, can be effective at assisting examination of the extent, range and nature of evidence on a topic (Tricco et al., 2018) as well as summarising findings from a heterogeneous body of knowledge, often necessary to inform healthcare practice models (Munn et al., 2018). The aim of this scoping review was to explore descriptions of occupational therapy interventions in addiction recovery treatment, synthesise these findings and to present information on interventions currently delivered.

\section{Methods}

The Preferred Reporting Items for Systematic Reviews and Meta-Analyses Extension for Scoping Reviews (PRISMA-ScR) (Tricco et al., 2018) was used to inform this review alongside Arksey and O'Malley's (2005) five-step scoping review framework includes the following:

- identifying the research question;

- identifying relevant studies;

- study selection;

- charting the data; and

- collating, summarising and reporting the results.

\section{Eligibility criteria}

Inclusion criteria was that articles described occupational therapy interventions as part of addiction treatment in any setting with adolescents, aged 13 and over, and/or adults and be published in English. We included articles published from 2000 to August 2019 to report on addiction interventions informed by Helbig and McKay's (2003) framework for addiction from an occupational perspective. Owing to the paucity of intervention descriptions in articles from peer-reviewed journals, and to generate a true representation of what occupational therapists are doing in this practice area, articles from non-peer-reviewed professional magazines were considered, as has occurred in scoping reviews previously (Paez, 2017). Study methodology or study design quality [appraised using the Crow Critical Appraisal Tool (CCAT)] was not used to exclude literature.
Articles were excluded if it was unclear what interventions were facilitated by an occupational therapist; if intervention description was linked only to theory, potential feasibility of an assessment or to smoking cessation programmes.

\section{Search strategy}

Databases included CINAHL-Complete, Scopus, PsycINFO and MEDLINE as these covered most peer-reviewed literature in this clinical area. Boolean terms were used to combine terms associated with the population and the topic. Search terms included occupational therapy, occupational therapist, OT, intervention, addiction, substance use/disorder/abuse/misuse, drug abuse/misuse and alcohol abuse/misuse. The reference lists of included articles were searched as were forward citations of key articles.

\section{Selection of sources}

The titles and abstracts of all articles were screened independently by both authors (DR and PB) using Rayyan software, who then compared results to agree on included articles.

\section{Data charting process}

The full text of each included article was read and data describing occupational therapy interventions were extracted. Data was extracted on the aims of the research/publication, demographics of people with substance use disorders, contexts in which occupational therapists were working, methods used to describe interventions and evaluate treatments and core research/publication findings.

\section{Critical appraisal}

The CCAT Form (Crow, 2013) was used to appraise all included articles. Two papers were independently appraised by both authors to calibrate use of this tool. Tricco et al. (2018) identified formal assessment of methodological quality as optional in scoping reviews however, critical appraisal informed understanding of the quality of research generally.

\section{Synthesis of results}

Similarities in practice and intervention focus were analysed and grouped thematically. Descriptions of interventions across papers were extracted and examined by DR. The key components of the research question were used to design initial mapping of key concepts of interest, consistent with scoping review methodology (Arksey and O'Malley, 2005) - namely, the outline of intervention design, delivery and intensity (where this information was available) and map-related outcomes for clients, their families and services. Thereafter, DR collated interventions under theme names which best captured the core theme of each paper. These theme categories were reviewed by PB to ensure coherency.

\section{Results}

\section{Selection of evidence}

A total of 432 citations were identified after removal of duplicates, thereafter 399 were excluded based on title and abstract. A total of 33 full-text articles were assessed and 15 
articles were excluded. Figure 1 depicts the screening process followed, based on PRISMA-ScR guidelines (Tricco et al., 2018).

\section{Characteristics of included articles}

Included articles are represented in the extraction document (Table 1). Of the 18 included articles, three were quantitative (Detweiler et al., 2015; Peloquin and Ciro, 2013a, 2013b), five were qualitative (Bell et al., 2015; Godoy-Vieira et al., 2018; Ribeiro et al., 2019; Stevens, 2003; Ussher et al., 2000), six were narrative descriptions of interventions (Gutman, 2006; Lakshmanan, 2014; Louie, 2012; Peloquin, 2010; Roush, 2008; Tayar, 2004) and four used mixed methods (Boisvert et al., 2008; Cardinale et al., 2014; Darko-Mensah, 2011; Wasmuth et al., 2016).

\section{Critical appraisal}

CCAT scores ranged from $6 / 40$ to $35 / 40$ (Table 2), with an average score of $21 / 40$ or $52 \%$ of standards met across all articles. Lowest scoring areas were design, sampling, data collection and ethical matters.

\section{Context of occupational therapy intervention}

Most research was conducted in the USA $(n=10)$ (Boisvert et al., 2008; Cardinale et al., 2014; Detweiler et al., 2015; Gutman, 2006; Peloquin, 2010; Peloquin and Ciro, 2013a, 2013b; Roush, 2008; Tayar, 2004; Wasmuth et al., 2016) with one each from UK (Ussher et al., 2000), New Zealand (Stevens, 2003), Canada (Darko-Mensah, 2011), Hong Kong
(Louie, 2012), India (Lakshmanan, 2014), South Africa (Bell et al., 2015), Brazil (Godoy-Vieira et al., 2018) and Portugal (Ribeiro et al., 2019).

Two studies focused on adolescents (Bell et al., 2015; Louie, 2012), four on women-only (Cardinale et al., 2014; Peloquin, 2010; Peloquin and Ciro, 2013a, 2013b), with one study each focused on veterans (Wasmuth et al., 2016) and prison populations (Tayar, 2004).

The findings are organised under the following three themes:

Single occupation focused intervention;

Skills training (sub-themes) on

- daily living skills; and

- (vocational skills).

Establishing a community-based sober routine.

\section{Single occupation focused intervention}

Four interventions consisted of a single focused occupation (Cardinale et al., 2014; Detweiler et al., 2015; Ussher et al., 2000; Wasmuth et al., 2016). Detweiler et al. (2015) used horticulture, which was the main intervention. The programme was greeted positively by participants, with reductions in cohort cortisol levels noted post intervention. Planning skills, responsibility and collaboration were built through engagement in garden education, planning and management.

Ussher et al. (2000) promoted fitness orientated physical activity, co-facilitated between an exercise specialist and an occupational therapist who supported engagement in exercise counselling, goal setting and weekly check-in sessions, which

Figure 1 PRISMA 2009 flow diagram

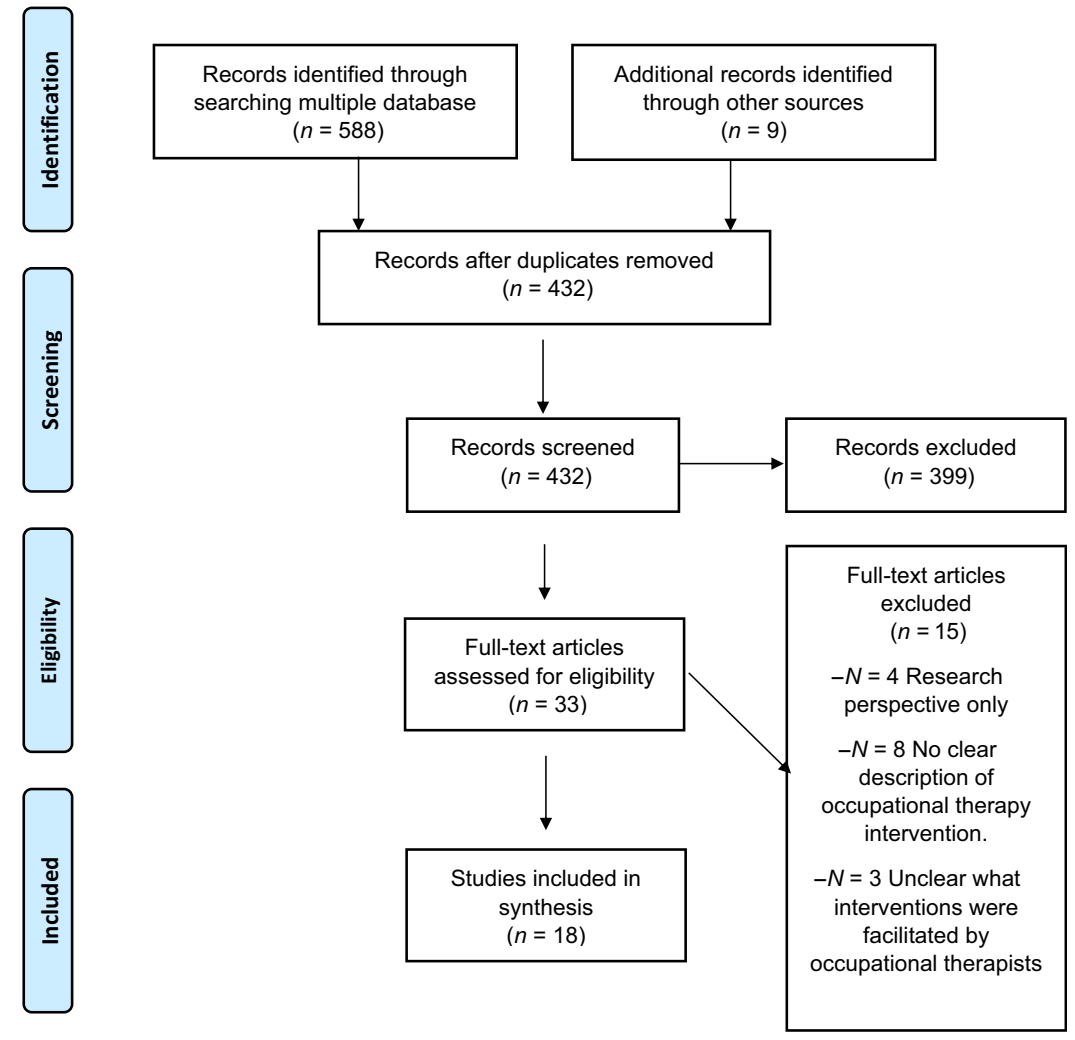


Table 1 Extraction table of included articles

\begin{tabular}{|c|c|c|c|c|}
\hline Citation & Research aims & $\begin{array}{l}\text { Context and } \\
\text { sample }\end{array}$ & Core findings & Description of OT intervention \\
\hline \multicolumn{5}{|l|}{ Quantitative papers } \\
\hline $\begin{array}{l}\text { Detweiler et al. } \\
\text { (2015) }\end{array}$ & $\begin{array}{l}\text { - To assess effects of horticulture } \\
\text { vs OT[1] on cortisol levels, } \\
\text { depression, PTSD[2] symptoms, } \\
\text { alcohol cravings and QoL[3] }\end{array}$ & $\begin{array}{l}\text { Inpatient } \\
24\end{array}$ & $\begin{array}{l}\text { - HT[4] and OT reduced stress } \\
\text { - No significant difference between } \\
\text { groups } \\
\text { - Saliva cortisol comparison not } \\
\text { possible as OT data un-useable } \\
\text { - HT showed cortisol decrease from } \\
\text { Week } 1 \text { to } 3 \text { but was not } \\
\text { statistically significant }\end{array}$ & $\begin{array}{l}\frac{\text { HT interventions }}{\text { - Gardening education }} \\
\text { - Garden management, planning \& } \\
\text { maintenance } \\
\text { OT interventions } \\
\text { - Crafts, ceramic painting and } \\
\text { leather work } \\
\text { - Model assembly and flower } \\
\text { arranging }\end{array}$ \\
\hline $\begin{array}{l}\text { Peloquin and Ciro } \\
\text { (2013a) }\end{array}$ & $\begin{array}{l}\text { Analysis of client satisfaction and } \\
\text { engagement } \\
\text { - Examine variance in perceptions } \\
\text { from PEO[5] focus } \\
\text { - Determine how perceptions } \\
\text { varied according to activity } \\
\text { demand }\end{array}$ & $\begin{array}{l}\text { Inpatient } \\
1,488 \text { surveys }\end{array}$ & $\begin{array}{l}\text { - 97\% satisfaction with group } \\
\text { engagement } \\
\text { - No significant variance in } \\
\text { engagement in PEO focused } \\
\text { groups } \\
\text { - No significant variance according } \\
\text { to activity demands so all groups } \\
\text { deemed equally successful in } \\
\text { engaging SU[6]s }\end{array}$ & $\begin{array}{l}\text { - Self-development group } \\
\text { - Motivational/didactic work and } \\
\text { discussion } \\
\text { - Creative activities on theme } \\
\text { - Relaxation }\end{array}$ \\
\hline $\begin{array}{l}\text { Peloquin and Ciro } \\
(2013 b)\end{array}$ & $\begin{array}{l}\text { Analysis of client satisfaction and } \\
\text { perceived engagement } \\
\text { - Examine variance in perceptions } \\
\text { from PEO focus } \\
\text { - Determine if perceptions varied } \\
\text { according to activity demand }\end{array}$ & $\begin{array}{l}\text { Inpatient } \\
561 \text { surveys }\end{array}$ & $\begin{array}{l}\text { - 96.8\% satisfaction with group } \\
\text { engagement } \\
\text { - No significant variance in } \\
\text { engagement in PEO focused } \\
\text { groups } \\
\text { - No significant variance according } \\
\text { to activity demands so all groups } \\
\text { deemed to successfully engage SUs }\end{array}$ & $\begin{array}{l}\text { - Living skills group } \\
\text { - Relaxation } \\
\text { - Skills development } \\
\text { - Role plays } \\
\text { - Task engagement }\end{array}$ \\
\hline \multicolumn{5}{|l|}{ Qualitative papers } \\
\hline Bell et al. (2015) & $\begin{array}{l}\text { Explore adolescent's perceptions } \\
\text { and influence of OT input within } \\
\text { addiction treatment }\end{array}$ & $\begin{array}{l}\text { Inpatient } \\
8 \text { adolescents } \\
1 \text { adult key } \\
\text { informant }\end{array}$ & $\begin{array}{l}\text { - Role restoration and maintenance } \\
\text { is vital } \\
\text { - Facilitation of skills practice } \\
\text { required } \\
\text { - Highlights importance of SU } \\
\text { perspective }\end{array}$ & $\begin{array}{l}\text { - Leisure exploration } \\
\text { - Vocational exploration } \\
\text { - Communication and } \\
\text { assertiveness skills } \\
\text { - Arts and crafts }\end{array}$ \\
\hline $\begin{array}{l}\text { Godoy-Vieira et al. } \\
\text { (2018) }\end{array}$ & $\begin{array}{l}\text {-To analyse the practices of OTs in } \\
\text { substance users' healthcare, } \\
\text { according to the purposes of their } \\
\text { practice }\end{array}$ & $\begin{array}{l}\text { Inpatient } \\
9 \text { OTs }\end{array}$ & $\begin{array}{l}\text { - Clients are agents of } \\
\text { transformation in health process } \\
\text { - Creativity is a strong element of } \\
\text { practice \& underlies the } \\
\text { therapeutic process } \\
\text { - Conditions of social reproduction } \\
\text { compose the object of OT } \\
\text { - Two approaches informed by the } \\
\text { labour-process purpose identified: } \\
\text { 1) Inclusive 2) Emancipatory }\end{array}$ & $\begin{array}{l}\text { - Creative activity practice and } \\
\text { facilitation } \\
\text { - Leisure exploration } \\
\text { - Life skills practice } \\
\text { - Goal setting } \\
\text { - Community integration } \\
\text { - Vocational exploration and skills } \\
\text { development }\end{array}$ \\
\hline Gutman (2006) & $\begin{array}{l}\text {-Describe underlying } \\
\text { neurochemical and genetic factors } \\
\text { of addiction } \\
\text { - Explore addiction treatment } \\
\text { - Relate research to OT role in } \\
\text { addiction }\end{array}$ & $\begin{array}{l}\text { Inpatient } \\
1 \text { case study }\end{array}$ & $\begin{array}{l}\text { - Neurological process of addiction } \\
\text { should inform addiction treatment } \\
\text { - OTs need to review the } \\
\text { neurological underpinning of } \\
\text { addiction \& revise treatment } \\
\text { accordingly } \\
\text { - Document service effectiveness } \\
\text { - Advocate OTs inclusion in } \\
\text { addiction rehab }\end{array}$ & $\begin{array}{l}\text { - Challenge distorted thinking to } \\
\text { facilitate appropriate thinking on } \\
\text { substance use implications } \\
\text { - Craving management through } \\
\text { education on sensory stimuli } \\
\text { - Social reintegration - Leisure } \\
\text { exploration } \\
\text { - Role development - Time } \\
\text { management }\end{array}$ \\
\hline
\end{tabular}


Table 1

Context and

Citation

Research aims
Core findings

- Purposeful activity that contributes to the individual or society is acceptable work - Work is a critical component to recovery

- OTs support task engagement \& achievement resulting in the building of self-esteem, selfconcept \& routines

Ribeiro et al. (2019) Describe the role of OT in addiction

Community clinic
Outpatient 1 intervention with SU experiencing substance misuse

Describe OT intervention in women only residential treatment programme rehabilitation in the named setting -Understand the SUs perceptions of the role of OT in addiction rehabilitation -Understand the perceptions of other team members of the role of OT in addiction rehabilitation
Inpatient 12 8

OTs $\mathrm{N}=2$

SUs $\mathrm{N}=2$

Psychologists $\mathrm{N}$

$=3$

Social Worker $\mathrm{N}$ $=1$

Outpatient 1 case study
- A multi-sector networking approach is vital to treat teens in addiction, to re-orientate them to meaningful activity \& support development to ensure recovery

- OT is a good fit in residential addiction treatment

- Clients identify success relies on recovering sober \& satisfying routines

- SUs identify OT supports hope \& identify it as valuable within the programme

- OTs identified as being supportive in areas of $A D L s$, IADLs, routine planning, leisure exploration, social participation, and cognitive rehabilitation

- OT is unique in its approach to supporting SUs through use of meaningful occupation

- Motivation and volition identified as being impacted positively by engagement in occupation which in turn support recovery

- OT identified as profession that supports individuals to realise their unique potential

Discuss how OT intervention is supportive for treating SUs with dual diagnosis
- OT play pivotal role in treatment of dual diagnosed as focus on occupational performance as recovery is supports through engagement in the community through meaningful engagement
Description of OT intervention

- Stress management - Drug refusal practice

- Support participation in group

programme

- Yoga, gym attendance, participation in games

- Drink refusal skills

- Crafts

- Provide work role within the

treatment service

- Support to build skill \& establish a recovery routine

- Gradual supported return to the community

- OT screening included cognitive function, memory \& fine motor skills assessment

- Routine planning

- Vocational exploration, planning and support

- Self Development - Didactic work

- Creative activities - Relaxation

- Living skills and goal settings

- Schedule planning and task engagement

- Skills development and role plays

- Vocational exploration

- Life skills development and practice

- Leisure exploration

- Facilitation of social participation

- Routine exploration and

development

- Goal setting \& motivation

- Cognitive support

- Development of occupational

profile

- Recovery lifestyle planning

- Role development

- Leisure participation - Social skills

- Stress management - Time

management

- Life skills i.e. money management \& ADL practice

(continued) 
Table 1

\begin{tabular}{ll}
\hline Citation & Research aims \\
\hline Stevens (2003) & $\begin{array}{l}\text { Describe OT intervention based on } \\
\left.\text { MOHO[7] with one SU }{ }^{8}\right] \text { with dual } \\
\text { diagnosis }\end{array}$ \\
Tayar (2004) & $\begin{array}{l}\text { Describe an OT \& Psychology } \\
\text { student co-facilitated relapse } \\
\text { prevention intervention within a } \\
\text { women's prison }\end{array}$
\end{tabular}

Ussher et al. (2000) Assess the effectiveness of physical intervention in community-based alcohol service

Outpatient community 5

Prison service Unknown

\section{Mixed methods papers}

Boisvert et al. (2008)

Cardinale (2014)

Darko-Mensah (2011)
Examine effectiveness of a peer support community model to address need for sustained recovery within a peer support housing facility

Facilitate and explore the "Tree Theme Model" to empower and support mothers in recovery

Develop, implement and evaluate a group programme aimed to investigate productivity success

\section{Context and}

sample

Inpatient

Peer support community house 10

Outpatient residential
Core findings

Description of OT intervention

- Significant prevalence of dual

diagnosis

Leisure exploration

- Client centred focus important to

- Vocational skills

facilitate recovery \& community

independence

- Feedback indicates SUs had positive experience - Inter-disciplinary working was positive for students

- Intervention combining counselling, discussion, advice \& supervised exercise had positive impact on participants

- Participants changed many health orientated behaviours simultaneously

- Co-facilitation was positive \& OT saw potential use for exercise in relapse prevention 3 adult mothers

Integrated day/ service 20
- Reduction in risk of relapse

- Improvement in QoL rating

- Qualitative evidence of improvements in perceived community affiliations and supportive behaviours

- The "Tree Themed Model" shown to be therapeutic

- Empowerment Programme successful in increasing personal growth initiatives for mothers in recovery

- SUs can discover potential when a forum is provided to attend to productivity

- Exploring vocational identity is an important component for inclusion in recovery services

- OTs can contribute to the development of productivity focused recovery services
- Organisational skills and routine scheduling

- Work project group

- Assertiveness and communication

- Community engagement

- Leisure exploration \& engagement

- Relaxation

- Personal exploration

- Vocational exploration

- Life skills i.e. budgeting \& skills-

based role play

- Routine planning and discharge preparation

- Promoting fitness orientated

physical activity

- Exercise counselling

- Goal setting and self-monitoring

- Relapse prevention

- Decision balance sheets

- Individual sessions on daily living skills

- Group sessions on occupational performance

- Facilitation of weekly group meetings at peer support community

- Facilitate and support community development

- Empowerment programme

- Progressive relaxation

- Facilitation and discussion on painting of a tree representing life, personality, occupation and interests

- Engagement with self-help books Vocational exploration

- Creation of group resume

- Completion of career inventory

- Review client research in interest area

- Goal setting 
Table

\begin{tabular}{|c|c|c|c|c|}
\hline Citation & Research aims & $\begin{array}{l}\text { Context and } \\
\text { sample }\end{array}$ & Core findings & Description of OT intervention \\
\hline $\begin{array}{l}\text { Wasmuth et al. } \\
\text { (2016) }\end{array}$ & $\begin{array}{l}\text { To explore the feasibility and } \\
\text { acceptability of theatre as a } \\
\text { community-engaging intervention } \\
\text { for veterans experiencing } \\
\text { substance use }\end{array}$ & 7 & $\begin{array}{l}\text { - Providing theatre as opportunity } \\
\text { for social and occupational } \\
\text { participation may support OT } \\
\text { outcomes in addiction recovery }\end{array}$ & $\begin{array}{l}\text { - Facilitating participation and } \\
\text { development of skills to participate } \\
\text { in drama } \\
\text { - Cognitive strategies } \\
\text { - Discussions linking character and } \\
\text { SU experience } \\
\text { - Discussions focused on the } \\
\text { impact of substance use on } \\
\text { occupational engagement }\end{array}$ \\
\hline
\end{tabular}

Table 2 Crow critical appraisal tool (CCAT) score of included articles

\begin{tabular}{|c|c|c|c|c|c|c|c|c|c|c|}
\hline Citation & Preliminaries & Introduction & Design & Sampling & Data collection & Ethical matters & Results & Discussion & Total & Total $(\%)$ \\
\hline Bell et al. (2015) & 4 & 5 & 4 & 4 & 5 & 5 & 4 & 4 & 35 & 88 \\
\hline Boisvert et al. (2008) & 4 & 5 & 4 & 3 & 4 & 4 & 4 & 4 & 32 & 80 \\
\hline Cardinale et al. (2014) & 3 & 3 & 3 & 1 & 3 & 3 & 2 & 2 & 20 & 50 \\
\hline Darko-Mensah (2011) & 1 & 1 & 1 & 1 & 2 & 0 & 2 & 1 & 9 & 23 \\
\hline Detweiler et al. (2015) & 5 & 5 & 4 & 4 & 3 & 5 & 3 & 3 & 32 & 80 \\
\hline Godoy-Vieira et al. (2018) & 4 & 5 & 3 & 3 & 3 & 3 & 4 & 5 & 30 & 75 \\
\hline Gutman (2006) & 5 & 5 & 0 & 0 & 0 & 0 & 5 & 5 & 20 & 50 \\
\hline Lakshmanan (2014) & 1 & 1 & 1 & 0 & 1 & 0 & 1 & 1 & 6 & 15 \\
\hline Louie (2012) & 2 & 1 & 1 & 1 & 1 & 0 & 1 & 1 & 8 & 20 \\
\hline Peloquin (2010) & 2 & 1 & 1 & 1 & 0 & 0 & 1 & 1 & 7 & 18 \\
\hline Peloquin and Ciro (2013a) & 4 & 5 & 3 & 3 & 3 & 3 & 4 & 4 & 29 & 73 \\
\hline Peloquin and Ciro (2013b) & 4 & 5 & 3 & 3 & 3 & 3 & 4 & 4 & 29 & 73 \\
\hline Ribeiro et al. (2019) & 3 & 3 & 3 & 2 & 3 & 3 & 3 & 1 & 21 & 53 \\
\hline Roush (2008) & 3 & 3 & 1 & 0 & 0 & 1 & 1 & 2 & 11 & 28 \\
\hline Stevens (2003) & 3 & 4 & 3 & 2 & 3 & 2 & 3 & 3 & 23 & 58 \\
\hline Tayar (2004) & 2 & 2 & 2 & 0 & 0 & 0 & 1 & 1 & 8 & 20 \\
\hline Ussher et al. (2000) & 2 & 4 & 4 & 2 & 3 & 4 & 3 & 1 & 23 & 58 \\
\hline Wasmuth et al. (2016) & 3 & 5 & 4 & 3 & 4 & 4 & 4 & 5 & 32 & 80 \\
\hline Total scores & $55 / 90$ & $63 / 90$ & $45 / 90$ & $33 / 90$ & $41 / 90$ & $40 / 90$ & $50 / 90$ & $48 / 90$ & $375 / 720$ & 52 \\
\hline
\end{tabular}

aimed to support self-monitoring, a vital skill for maintaining recovery.

Wasmuth et al. (2016) used drama, where participants were involved in the production of a co-facilitated play. The occupational therapist used rehearsals to develop cognitive strategies with participants. Facilitated discussions linked character experiences to the participants' issues, which was an accessible medium for them to acknowledge the difficult impact of substance use in their lives. The community element provided a safe, supportive space, which facilitated participants who relapsed during rehearsals to return to gain support.

Finally, Cardinale et al. (2014) reported on the "Tree Themed Model," with five semi-structured group sessions, including progressive relaxation exercises followed by members painting a tree to represent different parts of their life. Participants particularly valued insights gained during the creative process.

\section{Skills training}

Many publications reported that occupational therapy is well placed to support the development of skills (Bell et al., 2015;
Peloquin, 2010; Ribeiro et al., 2019; Roush, 2008; Stevens, 2003; Tayar, 2004). Skills development interventions fell into two categories: skills for daily life, i.e. activities of daily living (ADLs) including associated supportive skills, and skills required for work roles.

Daily living skills and interventions A total of 12 publications referred to life skills and personal development as core occupational therapy interventions. Time management and routine planning were common interventions, included in nine publications (Boisvert et al., 2008; Godoy-Vieira et al., 2018; Gutman, 2006; Louie, 2012; Ribeiro et al., 2019; Roush, 2008; Stevens, 2003; Tayar, 2004; Ussher et al., 2000). Three papers (Bell et al., 2015; Peloquin and Ciro, 2013a, 2013b; Ribeiro et al., 2019) outlined how life skills and personal development were used within inpatient settings. These publications presented individual and group interventions including role playing, communication, assertiveness, relaxation and social skills training. Boisvert et al. (2008) described interventions with community-dwellers, reporting on occupational capacity and interventions focused on ADL development, 
communication and personal development to support transition to live in a peer-supported community house.

Gutman (2006) supported life skill development in a case study, by drawing on the neurological process of addiction. Gutman linked life skill difficulties, e.g. stress management and reduced motivation, and goal achievement difficulties to the brain's neurological process of priming, which can lead to relapse. The case study participant was educated on how addiction has changed the brain's reward system. This learning facilitated the participant to build new supportive lifestyle habits.

Roush (2008) champions role-playing life skills and sobriety skills, advocating for the benefits of a multi-problem viewpoint and that advocated for using occupational profiles to support intervention planning with people experiencing addiction.

Vocational skills, exploration and interventions Nine studies discussed vocational interventions in addiction treatment, stressing the importance of work in preventing relapse. Seven interventions facilitated vocational exploration including creating Curriculum Vitaes (CVs), supporting job applications and discussing vocational preferences (Bell et al., 2015; DarkoMensah, 2011; Godoy-Vieira et al., 2018; Louie, 2012; Peloquin, 2010; Stevens, 2003; Tayar, 2004). Darko-Mensah's (2011) programme, "Career 101," focused solely on vocational exploration, education and work skills. Bell et al. (2015) and Tayar (2004) presented the benefits of vocational training with adolescents and female prison-based populations. Three studies honed in on participant's work roles (Lakshmanan, 2014; Louie, 2012; Stevens, 2003). Lakshmanan (2014) and Louie (2012) supported participants to develop a structured recovery through work. Stevens (2003) used work-focused groups where craft projects were created and sold at markets.

Providing a forum to explore productivity and engage in work roles supported participants to discover their potential, enabled identity development outside of addiction and facilitated inclusion, which is often lacking in early recovery (Darko-Mensah, 2011; Godoy-Vieira et al., 2018). Boisvert et al. (2008) reflected value in work roles from a community perspective where participants were facilitated to gradually take on responsibilities, work roles and leadership roles within the community house.

\section{Establishing a community-based sober routine}

A participant in Peloquin (2010) summarised this theme by stating long-term success for people with substance use disorders relies on recovering sober and satisfying lives. Roush (2008) recommends that skill learning should be followed by skill consolidation and goal setting. This supports the transfer of skills to the community creation of sober routines. Ribeiro et al. (2019), Tayar (2004); and Ussher et al. (2000) discussed the importance of routine planning and accessing recovery supports in establishing a sober lifestyle. Four studies reported on assertiveness skills (Bell et al., 2015; Gutman, 2006; Lakshmanan, 2014; Stevens, 2003) with Gutman (2006) and Lakshmanan (2014) moving to apply this skill further to support sobriety via drug/drink refusal skills.

Leisure exploration was central in eight studies (Bell et al., 2015; Godoy-Vieira et al., 2018; Lakshmanan, 2014; Peloquin, 2010; Ribeiro et al., 2019; Roush, 2008; Stevens, 2003; Tayar, 2004) to encourage community re-integration and establish non-addiction related routines. Ribeiro et al. (2019) presented that the discovery or rediscovery of meaningful leisure activities developed motivation, vital for the process of change. Ussher et al. (2000) and Wasmuth et al. (2016) discussed how establishing different leisure interests supported selfexploration and role development.

Using occupational therapy to support development of identity went beyond the facilitation of leisure interventions. One of the themes identified in Bell et al. (2015), "take us out to life," supports this theory, as participants indicated the occupational therapy intervention enabled planning and confidence in their future sober lives. Gutman (2006) highlights the neurological process of addiction when discussing community engagement, identifying new role development and social integration supports as vital components. Godoy-Vieira et al. (2018) reported that the establishment of a social identity beyond a substance user identity was a key role for occupational therapy. The importance of community identity was highlighted by Boisvert et al. (2008) when the success of their peer support community indicated the importance of community re-integration as beneficial for recovery.

\section{Discussion}

This review has illustrated that occupational therapy interventions related to addiction treatment are sparsely reported and rarely evaluated. Rojo-Mota et al. (2017) summarised that occupational therapy models were capable of explaining addiction from an occupational perspective but stated more research was required with regards to effectiveness. While effectiveness of interventions is not the core focus of this review, but rather what interventions are currently in use in daily clinical practice; indeed, occupational therapy is delivered in multiple ways across varied settings for people with substance use disorders. Illustrating the breadth of work in this area will hopefully increase development of occupational therapy interventions from acute to community-based settings. The increasing clarity on the design of occupational therapy interventions to support recovery for people experiencing addiction is encouraging, though the lack of empirical evidence on effectiveness needs to be addressed.

Most reported interventions were underpinned by development of life skills and supported re-engagement in meaningful routines. These interventions are central to occupational therapy practice to support people to move away from the dysfunctional impact of addictive behaviours. Life skills development were often embedded in existing treatment programmes, where occupational therapists engaged with service-users independently, but also as part of a wider team.

Of note, it is not enough to acquire skills, one also needs skills practice to support recovery. Feedback in Peloquin (2010) reflected that the facilitation of skills practice was the most valuable aspect of occupational therapy intervention. Across studies, people with substance use disorders were enabled to take control of their lives through engagement in occupation (Tayar, 2004; Wasmuth et al., 2016).

Facilitating skills practice and positive occupations supported service-users to make positive changes beyond occupational therapy interventions. Many studies noted this 
(Boisvert et al., 2008; Cardinale et al., 2014; Godoy-Vieira et al., 2018; Peloquin and Ciro, 2013a, 2013b; Ribeiro et al., 2019; Tayar, 2004; Wasmuth et al., 2016), but it was particularly prevalent in Ussher et al. (2000). A "chain reaction" effect occurred when service-users were supported to make one influential positive change, dispersing into other areas of life.

Interestingly, some interventions were not necessarily part of traditional addiction treatment programmes, i.e. those with an abstinence or harm reduction focus. These community intervention examples represented more novel interventions, i.e. exercise, theatre and horticulture. Another unexpected finding was the amount of narrative presentations of interventions present, one paper alone had an explicit research focus.

Finally, other than 10/18 USA-based papers, there was a broad geographical spread representing varied health-care systems and approaches to occupational therapy practice, so results should be interpreted with caution for specific countries and cultures.

\section{Recommendations}

Based on our findings, we recommend an increase in research on how occupational therapy is engaging with people with substance use disorders, a call being endorsed by others (Amorelli, 2016; Wasmuth et al., 2016). Some possible areas for priority include exploring the role of occupational therapy interventions to support people experiencing substance use and addictive behaviours within structured treatment programmes. Using qualitative or participatory research methods would be valuable to explore both a clinician and a service-user perspective. The CCAT scores for the studies in this review were mixed. Positively, there was what appears to be a growing quantity of research in this area, indicating recognition of the need for greater quantity and quality of evidence for occupational therapists working in this field. However, the low CCAT scores indicated a need for more high-quality empirical research focused on measuring interventions effectiveness.

The practice recommendations include the assertion that occupational therapy appears to be a good fit within addiction treatment. The included studies support occupational therapists to consider going beyond the teaching of skills alone and to prioritise occupational engagement and client-centred practice to support clients beyond a substance user identity (Godoy-Vieira et al., 2018). Wasmuth et al.'s (2015) metacognition research identified the addictive process impacts the skill of cognitive mastery. This impairment adversely affects the adoption and carryover of skills. Therapists are advised to remain cognisant of the neurological research on addiction, as well as that emerging from mental health field more generally (Gutman, 2006).

\section{Strengths and limitations}

To date no other review has synthesised descriptions of occupational therapy practice within addiction recovery treatment. This scoping review has presented findings which represent the start of a process of assessing the available literature to inform further research in this developing clinical area. Following the protocol for a scoping review facilitated rigorous searching and screening of literature, while using an evidence-based screening tool and completing a double screening in a blinded manner also adds to the rigor of the findings.

A more systematic review was not possible to address this research aim given the heterogeneity of the methods and study populations (Tricco et al., 2018). While our critical appraisal process is a strength of this paper, to enable as much relevant literature to be included as possible, some non-peer-reviewed papers were identified as lacking in rigour. We are wary of attributing outcomes to occupational therapy intervention that may not have been seen if sample sizes were larger or, in some cases research methods more rigorous. The challenge is now for clinicians to measure relevant outcomes, report on and publish interventions occurring in an ethical, rigorous manner.

\section{Conclusion}

This scoping review has outlined literature on occupational therapy interventions when working with people experiencing addiction. Interventions delivered by occupational therapists in addiction treatment are generally well received by clients and supportive to reducing the harm associated with addictive behaviours. Further research focused on interventions used within addiction recovery treatment are required, to provide clearer descriptions of how occupational therapy interventions are delivered used and applied in this clinical area, to increase the and share evidence-based practice.

\section{Key findings}

- Occupational therapy appears to be a good fit within most addiction treatment settings and that occupational therapy interventions are most supportive when intervention goes beyond the teaching of skills, to prioritise occupational engagement.

- More research evidence is required to understand clearly how occupational therapists are engaging with people with substance use disorders and addictive behaviours.

\section{What this study added}

This study presents a synthesis of how occupational therapy interventions have been used to treat people experiencing addiction and indicates that service-users report finding occupational therapy supportive and helpful; however, there is currently limited evidence for generalisability of these findings. Further research is required to best understand how to design and tailor occupational therapy within diverse treatment settings.

\section{Notes}

1. OT: Occupational therapy

2. PTSD: Post-traumatic stress disorder

3. QoL: Quality of life

4. HT: Horticultural therapy

5. PEO: Person environment occupation - model of practice used in occupational therapy

6. SU: Service user 
7. MOHO: Model of human occupation $=$ Model of occupational therapy practice

\section{References}

Amorelli, C. (2016), "Psychosocial occupational therapy interventions for substance-use disorders: a narrative review", Occupational Therapy in Mental Health, Vol. 32 No. 2, pp. 167-184, doi: 10.1080/0164212X.2015. 1134293.

Arksey, H. and O'Malley, L. (2005), “Scoping studies: towards a methodological framework", International fournal of Social Research Methodology, Vol. 8 No. 1, pp. 19-32, doi: 10.1080/ 1364557032000119616.

Bell, T., Wegner, L., Blake, L., Jupp, L., Nyabenda, F. and Turner, T. (2015), “Clients' perceptions of an occupational therapy intervention at a substance use rehabilitation Centre in the Western Cape", South African Fournal of Occupational Therapy, Vol. 45 No. 2, pp. 10-14, doi: 10.17159/23103833/2015/V45N2A3.

Boisvert, R., Martin, L., Grosek, M. and Claire, A. (2008), "Effectiveness of a peer-support community in addiction recovery: participation as intervention", Occupational Therapy International, Vol. 15 No. 4, pp. 205-220, doi: 10.1002/oti.257.

Cardinale, J., Malacari, L., Broggi, S., Savignano, J. and Fisher, G. (2014), "Model of occupational empowerment and Gunnarsson's tree theme: intervention for mothers in recovery", Occupational Therapy in Mental Health, Vol. 30 No. 1, pp. 43-68, doi: 10.1080/0164212x.2014.878237.

Crow, M. (2013), "Crowe critical appraisal tool (CCAT) form (v1.4)", available at: https://conchra.com.au/wp-content/ uploads/2015/12/CCAT-form-v1.4.pdf (accessed 7 October 2018)

Darko-Mensah, A. (2011), "Working in addictions: the development, implementation and evaluation of the pilot group career exploration 101", Occupational Therapy Now, Vol. 13 No. 6, pp. 5-6.

Detweiler, M.B., Self, J.A., Lane, S., Spencer, L., Lutgens, B., Kim, D.Y., Halling, M.H., Rudder, T.C. and Lehmann, L. P. (2015), "Horticultural therapy: a pilot study on modulating cortisol levels and indices of substance craving, posttraumatic stress disorder, depression, and quality of life in veterans", Alternative Therapies in Health and Medicine, Vol. 21 No. 4, pp. 36-41.

Godoy-Vieira, A., Soares, C.B., Cordeiro, L. and Sivalli Campos, C. (2018), "Inclusive and emancipatory approaches to occupational therapy practice in substanceuse contexts", Canadian fournal of Occupational Therapy, Vol. 85 No. 4, pp. 307-317, doi: 10.1177/ 0008417418796868.

Gutman, S. (2006), "Why addiction has a chronic, relapsing course. The neurobiology of addiction", Occupational Therapy in Mental Health, Vol. 22 No. 2, pp. 1-29, available at: https://pdfs.semanticscholar.org/23b4/ed866b46243 376e184dd3ec6942f622ae101.pdf (accessed 20 November 2018).

Helbig, K. and McKay, E. (2003), "An exploration of addictive behaviours from an occupational perspective", fournal of
Occupational Science, Vol. 10 No. 3, pp. 140-145, doi: 10.1080/14427591.2003.9686521.

Hossack, J.R. (1952), "Clinical trial of occupational therapy in the treatment of alcohol addiction", American fournal of Occupational Therapy, Vol. 6 No. 6, pp. 265-282.

Lakshmanan, S. (2014), "Occupational therapy structured activities for substance use recovery", World Federation of Occupational Therapists Bulletin, Vol. 70 No. 1, pp. 30-31, doi: 10.1179/otb.2014.70.1.008.

Lancaster, J. and Chacksfield, J. (2014), "“Substance misuse”, Bryant, W., Fieldhouse, J., Bannigan, K., Creek, J. and Lougher, L. (Eds) Creek's Occupational Therapy and Mental Health, 5th ed, Churchill Livingstone, London, pp. 439-456.

Louie, F. (2012), "Occupational therapy and substance abuse: case study of a teen", World Federation of Occupational Therapists Bulletin, Vol. 66 No. 1, pp. 38-39, doi: 10.1179/ otb.2012.66.1.014.

Munn, Z., Peter, M., Stern, C., Tufanaru, C., McArthur, A. and Aromataris, E. (2018), "Systematic review or scoping review? Guidance for authors when choosing between a systematic or scoping review approach", BMC Medical Research Methodology, Vol. 18 No. 1, doi: 10.1186/s12874018-0611-x.

NICE (2010), "National institute for health and clinical excellence. Alcohol use disorders: diagnosis and clinical management of alcohol-related physical complications", available at: www.nice.org.uk/guidance/CG100 (accessed 1 December 2018).

Paez, A. (2017), "Gray literature: an important resource in systematic reviews", fournal of Evidence-Based Medicine, Vol. 10 No. 3, pp. 233-240, doi: 10.1111/jebm.12266.

Peloquin, S. (2010), "Occupational therapy among women in recovery from addiction", OT Practice, Vol. 24, pp. 12-22.

Peloquin, S. and Ciro, C. (2013a), "Self-development groups among women in recovery: client perceptions of satisfaction and engagement", American fournal of Occupational Therapy, Vol. 67 No. 1, pp. 82-90, doi: 10.5014/ajot.2013.004796.

Peloquin, S. and Ciro, C. (2013b), "Population-centered life skills groups: perceptions of satisfaction and engagement", The American fournal of Occupational Therapy, Vol. 67 No. 5, pp. 594-600, doi: 10.5014/ajot.2013.008425.

Ribeiro, J., Mira, E., Lourenço, I., Santos, M. and Braúna, M. (2019), "Intervenção da terapia ocupacional na toxicodependência: estudo de caso na comunidade terapêutica clínica do outeiro - Portugal”, Ciência E Saúde Coletiva, Vol. 24 No. 5, pp. 585-1596, doi: 10.1590/141381232018245.04452019.

Rojo-Mota, G., Pedrero-Pérez, E. and Huertas-Hoyas, E. (2017), "Systematic review of occupational therapy in the treatment of addiction: models, practice, and qualitative and quantitative research", American Fournal of Occupational Therapy, Vol. 71 No. 5, pp. 1-11, doi: 10.5014/ ajot.2017.022061.

Roush, S. (2008), "Occupational therapy and co-occurring disorders of mental illness and substance abuse", Special Interest Section Quarterly: Mental Health, Vol. 31 No. 2.

Stevens, H., Redfearn, S. and Tse, S. (2003), "Occupational therapy for people with dual diagnosis: a single case study", British Fournal of Therapy and Rehabilitation, Vol. 10 No. 4, pp. 166-173. 
Tayar, S. (2004), "Description of a substance abuse relapse prevention programme conducted by occupational therapy and psychology graduate students in a United States women's prison", British fournal of Occupational Therapy, Vol. 67 No. 4, pp. 159-166, doi: 10.1177/030802260 406700404

Thompson, K. (2007), “Occupational therapy and substance use disorders: are practitioners addressing these disorders in practice?", Occupational Therapy in Health Care, Vol. 21 No. 3, pp. 61-77, doi: 10.1080/j003v21n03_04.

Tricco, A., Lillie, E., Zarin, W., O'Brien, K., Colquhoun, H., Levac, D., Moher, D., Peters, M., Horsley, T., Weeks, L., Hempel, S., Akl, E., Chang, C., McGowan, J., Stewart, L., Hartling, L., Aldcroft, A., Wilson, M., Garritty, C., Lewin, S., Godfrey, C., Macdonald, M., Langlois, E., SoaresWeiser, K., Moriarty, J., Clifford, T., Tunçalp, Ö. and Straus, S. (2018), "PRISMA extension for scoping reviews (PRISMA-ScR): checklist and explanation", Annals of Internal Medicine, Vol. 169 No. 7, pp. 467-473, doi: 10.7326/ m18-0850.

United Nations Office on Drugs and Crime (2017), "World drug report 2017", available at: www.unodc.org/wdr2017/ field/Booklet_1_EXSUM.pdf (accessed 1 December 2018).

Ussher, M., McCusker, M., Morrow, V. and Donaghy, M. (2000), "A physical activity intervention in a community alcohol service", British fournal of Occupational Therapy,
Vol. 63 No. 12, pp. 598-604, doi: 10.1177/03080226 0006301207.

Wasmuth, S., Crabtree, J. and Scott, P. (2014), "Exploring addiction-as-occupation", British Fournal of Occupational Therapy, Vol. 77 No. 12, pp. 605-613, doi: 10.4276/ $030802214 X 14176260335264$.

Wasmuth, S., Pritchard, K. and Kaneshiro, K. (2016), "Occupation-based intervention for addictive disorders: a systematic review", Fournal of Substance Abuse Treatment, Vol. 62, pp. 1-9, doi: 10.1016/j.jsat.2015.11.011.

Wasmuth, S., Outcalt, J., Buck, K., Leonhardt, B., Vohs, J. and Lysaker, P. (2015), "Metacognition in persons with substance abuse: findings and implications for occupational therapists", Canadian fournal of Occupational Therapy, Vol. 82 No. 3, pp. 150-159, doi: 10.1177/0008417 414564865.

World Health Organization (2013), "Substance abuse", available at: www.who.int/topics/substance_abuse/en/ (assessed 28 March 2019).

World Health Organization (2014), 'Global Status Report on Alcohol and Health 2014', available at: www.who.int/ substance_abuse/publications/alcohol_2014/en/ (accessed 20 November 2018).

\section{Corresponding author}

Deirdre Anne Ryan can be contacted at: deeryanot@gmail. com 